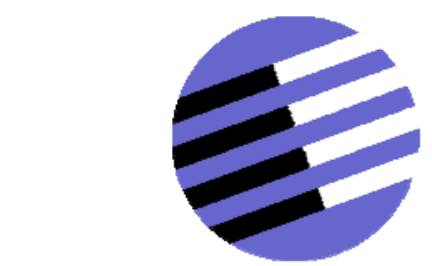

GOVERNANCE AND THE EFFICIENCY

OF ECONOMIC SYSTEMS

GESY

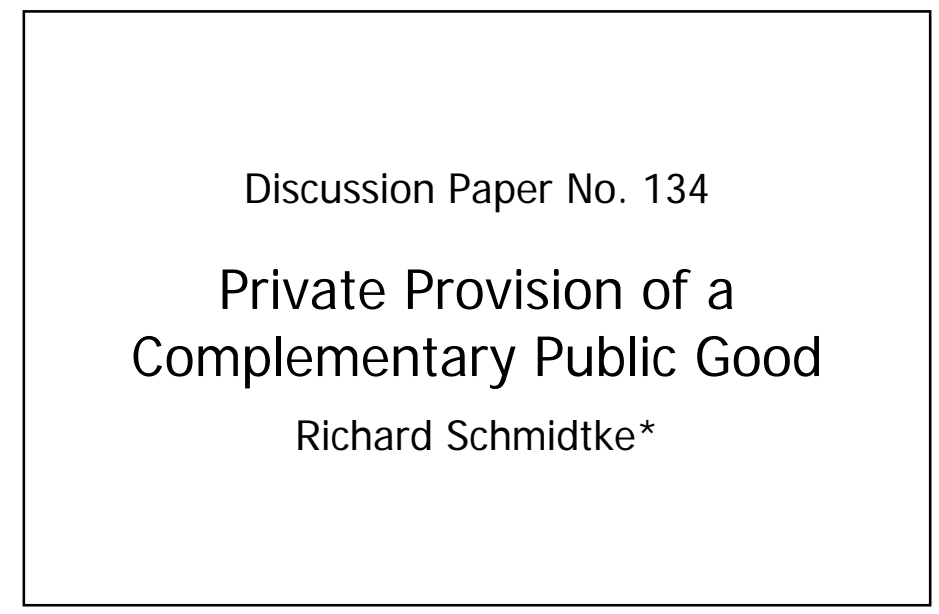

June 2006

* Richard Schmidtke, Department of Economics, University of Munich, Akademiestr. 1/III, 80799 Munich, Germany, Tel: +49-89-2180 3957, Fax: +49-89-2180 2767, Richard.Schmidtke@Irz.uni-muenchen.de

Financial support from the Deutsche Forschungsgemeinschaft through SFB/TR 15 is gratefully acknowledged. 


\title{
Private Provision of a Complementary Public Good*
}

\author{
Richard Schmidtke ${ }^{\dagger}$ \\ University of Munich
}

June 23, 2006

\begin{abstract}
For several years, an increasing number of firms are investing in Open Source Software (OSS). While improvements in such a nonexcludable public good cannot be appropriated, companies can benefit indirectly in a complementary proprietary segment. We study this incentive for investment in OSS. In particular we ask how (1) market entry and (2) public investments in the public good affects the firms' production and profits. Surprisingly, we find that there exist cases where incumbents benefit from market entry. Moreover, we show the counter-intuitive result that public spending does not necessarily lead to a decreasing voluntary private contribution.
\end{abstract}

JEL-classification numbers: C72, L13, L86

Keywords: Open Source Software, Private Provision of Public Goods, CournotNash Equilibrium, Complements, Market Entry

\footnotetext{
*I would like to thank Karolina Leib, Thomas Müller, Sougata Poddar, Ludwig Ressner, Monika Schnitzer, Jean Tirole, Christian Traxler and Patrick Waelbroeck and participants at the EDGE Jamboree in Marseille, at the International Industrial Organization Conference in Chicago, at the Society for Economic Research on Copyright Issues Annual Conference in Torino, at the Kiel-Munich Workshop in Kloster Seeon, at the E.A.R.I.E. in Berlin, at the Annual Meeting of the Verein fuer Socialpolitik in Dresden and at the IT Workshop in Toulouse for helpful comments and suggestions. I am grateful for financial support from the "Kurt Fordan Förderverein". Parts of this paper were written at the University of Toulouse. I am very grateful for the hospitality and the support that I received during my stay. Financial support from the Deutsche Forschungsgemeinschaft through SFB/TR 15 is gratefully acknowledged.

$\dagger$ Department of Economics, University of Munich, Akademiestr. 1/III, 80799 Munich, Germany, Tel.: +49-89-2180 3953, Fax.: +49-89-2180 2767, e-mail: Richard.Schmidtke@lrz.uni-muenchen.de
} 


\section{Introduction}

An increasing number of firms, like IBM and Hewlett-Packard or Suse and Red Hat, have begun to invest in Open Source Software. Open Source Software, such as Linux, is typically under the General Public License. This license implies that the software, including any improvement, has to be provided for free. Hence, an Open Source Software can be seen as a non-excludable public good. Therefore, firms are not able to sell the Open Source Software or their improvements. This raises the question why companies invest in such a public good.

Lerner and Tirole (2000) argue that firms expect to benefit from some market segment the demand of which is boosted by the improvement of a complementary Open Source Software. Even though the companies cannot directly capture the value of an open source program's improvement, they can profit indirectly through selling more complementary proprietary goods at a potentially higher price.

This incentive to invest in a non-excludable public good does not only arise in the case of Open Source Software. For example, a similar argument could be made in the case of advertising that increases the demand of the advertising firm and at the same time the demand of its competitors. Friedman (1983) calls this "cooperative advertising". Another example are lobby-activities of a firm that have a positive effect on the whole industry.

In this paper we study the incentive of firms to invest in such a non-excludable public good. In particular we address the following two questions:

(1) What is the effect of a higher public good investment by the government on the firms' output levels and profits?

(2) How does market entry affect the private incentive to invest in the public good? Furthermore, how does market entry influence the incumbents' profits?

We contribute to answer the questions (1) and (2) by analyzing a model with Cournot competition. Firms can produce a private good, and they can invest in a non-excludable public good in order to enhance its quality. However, they can only sell the private good. The private good and the public good are complements for the consumers. An increase in the quality of the public good increases their 
willingness to pay for the private good.

The first question is particularly interesting because of the ongoing discussion whether or not the government should support Open Source Software and if so, how. ${ }^{1}$ A concern might be that higher government investment in the public good decreases firms' investments as it is known from the public good literature. ${ }^{2}$ Hence, one usually expects a crowding out. Interestingly, such a crowding out does not have to take place with a complementary public good. We show that it might occur that the firms' investments increase if the government increases its investment in the public good. Hence, a crowding in can occur. Thus, it is not obvious whether the government investment in the public good is a strategic substitute or complement to the firms' public good investment.

The second question is shortly addressed by Lerner and Tirole (2000). They argue that the usual free-rider problem might appear because firms are not able to capture all the benefits of their investments. Therefore, one might argue that the free-rider problem gets worse with an increasing number of firms. Hence, a firm's investment in the public good decreases with market entry. As we will show in our model, it might occur that the opposite happens and thus each firm invests more. Furthermore, we show that market entry of an additional firm has a positive externality (through the entrant's investment in the public good) and a negative externality (through the entrant's production of the private good) on the incumbents. We find that for certain cost and demand functions each firm reduces its private good production and its public good investment when market entry occurs. In this case incumbents suffer a decrease in profits and dislike market entry. Surprisingly, for certain cost and demand constellations it is also possible that every firm expands its investment in the public good, combined with a higher private good output, when market entry occurs. In this case market entry increases the incumbents' profits. However, a social planer unambiguously prefers market entry.

This paper is related to the public good literature that is concerned with the private provision of a non-excludable public good. In standard models of private provision of a public good, households can buy the private good, they can

\footnotetext{
${ }^{1}$ See e.g. Hahn (2002), Evans and Reddy (2003) or Schmidt and Schnitzer (2002).

2 e.g Bergstrom et al. (1986)
} 
contribute to the public good, and they face a budget constraint. ${ }^{3}$ A household receives utility directly from the consumption of both goods and has to decide how to allocate his budget between the two goods. This setup differs from our model. We consider agents that have no direct benefit from the public good. The firms produce the public good solely due to the complementarity. Furthermore, firms face no budget constraint.

A second strand of literature our paper is related to is the literature on Multimarket Oligopoly. Bulow et al. (1985) analyze the spillovers of a change in one market environment on the related markets. In contrast to their model, in our model the markets are not related via the production technology, but via the demand function. Bulow et al. (1985) address this issue, but do not formalize it. They mention that firms have to take care of cross-effects in making marginal revenue calculations. Moreover, firms have to consider the strategic effects of their actions in one market on the competitors' actions in a second market. In our model we extend this setup to the case of a non-excludable public good. This is in contrast to the model of Bulow et al. (1985) where only private goods are considered.

Becker and Murphy (1993) analyze a model in which advertisement and an advertised good enter the utility function of the households. Advertisement has the property that it rises the willingness to pay for the advertised good. Hence, it is complementary to the advertised good from an economic point of view. Nevertheless, a firm's advertisement is only complementary to its own private good in their setup. By contrast, in our model it is also complementary to their competitors' private good.

Friedman (1983) considers, as a special case, cooperative advertising in a dynamic setup. He models advertising like capital in such a way that a firm can use advertising to build up a "goodwill stock". The firms have to decide how much to spend on advertising and how to allocate these spendings over time. By using "a symmetric quadratic model", he shows that an increasing number of active firms leads to a steady-state in which conventional competitive effects dominate.

\footnotetext{
${ }^{3}$ See e.g. Bergstrom et al. (1986) for a general approach and e.g Bitzer and Schröder (2002) or Johnson (2002) for an application to Open Source Software.
} 
Hence, prices converge to marginal costs. In contrast, we look at a static game to concentrate explicitly on the externalities between the firms. As we will see, this leads to different results.

We will proceed as follows. In the next section we set up the model. In Section 3 we look at the properties of the market equilibrium. In Section 4 we analyze the consequences of a government investment in the public good. In Section 5 we consider the effects of market entry. The final section concludes.

\section{The Model}

We assume that firms are engaged in a one-period Cournot competition. They decide simultaneously about their private good production and their investment in the public good, taking as given the competitors' production and investment. We denote by $x_{i}\left(x_{i} \in\left[0 ; \bar{x}_{i}\right]\right)$ the firm $i$ 's $(i \in\{1, \ldots, N\})$ production of the homogenous private good. By $y_{i}\left(y_{i} \in\left[0 ; \bar{y}_{i}\right]\right)$ we denote the firm $i$ 's investment in the homogenous non-excludable public good. Such an investment increases the quality of the public good linearly $Y=\sum_{i=1}^{N} y_{i} \cdot{ }^{4}$ The private good and the public good are complements for the consumers. Their willingness to pay for the private good is increasing in the quality of the public good and hence in the firms' public good investments. For an illustration consider a computer server (=the private good) and an Open Source Software (=the public good). The performance of the server depends crucially on the ability of the server operating system to use the power of the hardware. If the quality of the operating system increases, then the consumers' willingness to pay for the server increases due to the better performance. This yields the following private good demand function

$$
\begin{aligned}
& p=p\left(x_{i}, y_{i}, X_{-i}, Y_{-i}\right), \\
& \frac{\partial p}{\partial x_{i}}<0, \forall i \in\{1,2, \ldots, N\}, \\
& \frac{\partial p}{\partial y_{i}}>0, \forall i \in\{1,2, \ldots, N\} .
\end{aligned}
$$

\footnotetext{
${ }^{4}$ Throughout this paper we speak about quality of the public good. In some cases, like advertising, one can interpret this quality as a measure of quantity.
} 
We denote by $X_{-i}=\sum_{j=1 ; j \neq i}^{N} x_{j}$ the other firms' production of the private good. By $Y_{-i}=\sum_{j=1 ; j \neq i}^{N} y_{j}$ we denote the other firms' investment in the public good.

Furthermore, we have the following revenue function of firm $i$

$$
R_{i}\left(x_{i}, y_{i}, X_{-i}, Y_{-i}\right)=x_{i} p\left(x_{i}, y_{i}, X_{-i}, Y_{-i}\right)
$$

and the following profit function

$$
\pi_{i}=R_{i}\left(x_{i}, y_{i}, X_{-i}, Y_{-i}\right)-K^{x}\left(x_{i}\right)-K_{i}^{y}\left(y_{i}\right)
$$

We denote by $K^{x}\left(x_{i}\right)$ the private good cost function. For simplicity, we assume that this cost function is the same for all firms. We assume that firm $i$ has to incur the costs $K_{i}^{y}\left(y_{i}\right)$ for investing $y_{i}$ in the public good. Hence, we call this function "public good cost function". Furthermore, we assume that the public good cost function can be different for different firms.

In order to have a well defined maximization problem, we assume that the profit function $\pi_{i}$ is continuous and strictly concave in $x_{i}$ and $y_{i}$. The following conditions, satisfied for all $\left(x_{i}, y_{i}\right)$, yield a Hessian matrix that is everywhere negative definite. This is a sufficient condition for a strictly concave profit function.

$$
\begin{aligned}
& \text { Condition 1: } \frac{\partial^{2} \pi_{i}}{\partial x_{i}^{2}}<0 \\
& \text { Condition 2: } \frac{\partial^{2} \pi_{i}}{\partial y_{i}^{2}}<0 ; \\
& \text { Condition 3: } \frac{\partial^{2} \pi_{i}}{\partial x_{i}^{2}} \frac{\partial^{2} \pi_{i}}{\partial y_{i}^{2}}>\left[\frac{\partial^{2} \pi_{i}}{\partial x_{i} \partial y_{i}}\right]^{2}
\end{aligned}
$$


In order to satisfy Condition 1, we assume that the private good cost function is convex $\frac{\partial^{2} K^{x}\left(x_{i}\right)}{\partial x_{i}^{2}} \geq 0$ and that the revenue function is strictly concave $\frac{\partial^{2} R_{i}}{\partial x_{i}^{2}}<0$. For example, a concave demand function $\frac{\partial^{2} p}{\partial x_{i}^{2}} \leq 0$ is sufficient for a strictly concave revenue function.

In order to satisfy Condition 2, we assume a concave revenue function and a convex public good cost function, with at least one strict, because subtracting a convex (strictly convex) function from a strictly concave (concave) function yields a strictly concave function.

$$
\frac{\partial^{2} R}{\partial y^{2}} \leq 0 \text { and } \frac{\partial^{2} K_{i}^{y}\left(y_{i}\right)}{\partial y_{i}^{2}} \geq 0, \text { at least one strict. }
$$

For example, a concave demand function $\frac{\partial^{2} p}{\partial y_{i}^{2}} \leq 0$ yields a strictly concave profit function if the public good cost function is strictly convex.

In order to satisfy Condition 3 , we have to assume that

$$
\begin{aligned}
& {\left[\frac{\partial^{2} R_{i}}{\partial x_{i}^{2}}-\frac{\partial^{2} K^{x}}{\partial x_{i}^{2}}\right]\left[\frac{\partial^{2} R_{i}}{\partial y_{i}^{2}}-\frac{\partial^{2} K_{i}^{y}}{\partial y_{i}^{2}}\right]>\left[\frac{\partial^{2} R_{i}}{\partial x_{i} \partial y_{i}}\right]^{2},} \\
& \Leftrightarrow\left[2 \frac{\partial p}{\partial x_{i}}+x_{i} \frac{\partial^{2} p}{\partial x_{i}^{2}}-\frac{\partial^{2} K^{x}}{\partial x_{i}^{2}}\right]\left[x_{i} \frac{\partial^{2} p}{\partial y_{i}^{2}}-\frac{\partial^{2} K_{i}^{y}}{\partial y_{i}^{2}}\right]>\left[x_{i} \frac{\partial^{2} p}{\partial x_{i} \partial y_{i}}+\frac{\partial p}{\partial y_{i}}\right]^{2} .
\end{aligned}
$$

The stationary point does not have to be a maximum without this technical assumption.

\section{Market Equilibrium}

In this section we solve the game and determine the three different kinds of market equilibria. We show that a unique equilibrium can exist if the marginal costs of the public good are increasing. In contrast, a multiplicity of equilibria may arise if the marginal costs of the public good are constant.

We start with the case of increasing marginal costs of the public good. 
Proposition 1. Suppose that the public good's marginal costs are increasing. There exists a unique Nash Equilibrium where the firms produce $x^{*}=\left(x_{1}^{*}, x_{2}^{*}, \ldots, x_{N}^{*}\right)$ of the private good and invest $y^{*}=\left(y_{1}^{*}, y_{2}^{*}, \ldots, y_{N}^{*}\right)$ in the public good if

$$
(N-1)\left|x_{i} \frac{\partial^{2} p}{\partial x_{i} \partial x_{j}}+\frac{\partial p}{\partial x_{j}}\right|+N\left|x_{i} \frac{\partial^{2} p}{\partial x_{i} \partial y_{j}}+\frac{\partial p}{\partial y_{j}}\right|+\left(\frac{\partial^{2} p}{\partial x_{i} \partial x_{i}} x_{i}+2 \frac{\partial p}{\partial x_{i}}\right)<\frac{\partial^{2} K^{x}\left(x_{i}\right)}{\partial x_{i} \partial x_{i}}, \forall i
$$

and

$$
(N-1)\left|x_{i} \frac{\partial^{2} p}{\partial y_{i} \partial x_{j}}\right|+\left|x_{i} \frac{\partial^{2} p}{\partial y_{i} \partial x_{i}}+\frac{\partial p}{\partial x_{i}}\right|+(2-N) x_{i} \frac{\partial^{2} p}{\partial y_{i} \partial y_{j}}<\frac{\partial^{2} K_{i}^{y}\left(y_{i}\right)}{\partial y_{i} \partial y_{i}}, \forall i
$$

Proof. See Appendix.

In order to see the intuition behind Proposition 1, we write down firm $i$ 's profit function

$$
\pi_{i}=x_{i} p\left(x_{i}, X_{-i}, y_{i}, Y_{-i}\right)-K^{x}\left(x_{i}\right)-K_{i}^{y}\left(y_{i}\right) .
$$

Profit maximization yields the following first order conditions

$$
\begin{aligned}
& \frac{\partial \pi_{i}}{\partial x_{i}}=p+x_{i} \frac{\partial p}{\partial x_{i}}-\frac{\partial K^{x}\left(x_{i}\right)}{\partial x_{i}}=0, \\
& \frac{\partial \pi_{i}}{\partial y_{i}}=x_{i} \frac{\partial p}{\partial y_{i}}-\frac{\partial K_{i}^{y}\left(y_{i}\right)}{\partial y_{i}}=0 .
\end{aligned}
$$

Equation (15) displays the standard optimality condition. It says that the marginal costs of the private good have to be equal to the marginal revenue of the private good. Equation (16) shows that the investment in the public good has only an indirect effect on the profit. If the public good's quality increases, then the consumers' willingness to pay increases. This rises the price of the private good. Therefore, the revenue of firm $i$ increases.

Proposition 1 states that there is a unique Nash Equilibrium $x^{*}$ and $y^{*}$. From the Equations (15) and (16) we see that the production of the private good can 
reinforce the incentive to invest in the public good and vice versa. In order to illustrate this, consider an increase in the private good production of firm $i$. This increases the incentive to invest in the public good. A higher public good investment increases the price of the private good. Compared to the situation with a lower private good production, this price increase works on more private good units. Hence, for a firm it gets more attractive to invest in the public good if its private good production increases. ${ }^{5}$

At the same time, a higher public good investment also increases the incentives to produce the private good. The public good investment leads to a higher price of the private good because it increases the consumers' willingness to pay. Therefore, selling an additional unit gets more attractive because a firm earns a higher price out of the additional unit sold. ${ }^{6}$ But once again, this higher output level can yield a higher incentive to invest in the public good. Hence, the incentives to produce the private good and to invest in the public good can reinforce each other.

Conditions 1-3 ensure that this described process converges to a unique maximum for each firm if one takes the production and investment of the other firms as given. In order to determine the Nash-Equilibrium, we additionally have to take into account that the investment of a firm in the public good increases the incentive to produce the private good for all other firms. This may increase the other firms' incentive to invest in the public good and so on.

The two technical assumptions of Proposition 1 guarantee a unique NashEquilibrium $\left(x^{*}, y^{*}\right)$ by ensuring a contraction mapping of the best response functions. Hence, the equilibrium $\left(x^{*}, y^{*}\right)$ is globally stable and therefore unique.

In the two next propositions we consider constant marginal costs of the public good. We show that a multiplicity of equilibria or an asymmetric equilibrium arises.

Proposition 2. Suppose that the public good's marginal costs are constant and

\footnotetext{
${ }^{5}$ Of course, this is only true if the effect of the cross derivative $\frac{\partial^{2} p}{\partial x_{i} \partial y_{i}}$ does not work in the opposite direction and dominates.

${ }^{6}$ Of course, as above, this is only true if the effect from the cross derivative $\frac{\partial^{2} p}{\partial x_{i} \partial y_{i}}$ does not work in the opposite direction and dominates.
} 
equal for all firms. There are an infinite number of equilibria. In all equilibria $x_{i}^{*}$ is the same and the firms' investment in the public good always sums up to a certain level $Y^{*}$ if the following condition is fulfilled

$$
(N-1)\left|x_{i} \frac{\partial^{2} p}{\partial x_{i} \partial x_{j}}+\frac{\partial p}{\partial x_{j}}\right|+N\left|x_{i} \frac{\partial^{2} p}{\partial x_{i} \partial y_{j}}+\frac{\partial p}{\partial y_{j}}\right|+\left(\frac{\partial^{2} p}{\partial x_{i} \partial x_{i}} x_{i}+2 \frac{\partial p}{\partial x_{i}}\right)<\frac{\partial^{2} K^{x}\left(x_{i}\right)}{\partial x_{i} \partial x_{i}} .
$$

Proof. See Appendix.

In contrast to Proposition 1, Proposition 2 states that all public good investment vectors $y=\left(y_{1}, \ldots, y_{N}\right)$ that sum up to $Y^{*}=\sum_{i=1}^{N} y_{i}$ are Nash-Equilibria. In the previous case the individual investment level $y_{i}^{*}$ was determined by the increasing marginal costs. If these are constant, then a coordination problem between the firms occurs. For an illustration suppose two firms that produce the same quantities of the private good. Suppose that firm 1 assumes that firm 2 invests nothing in the public good. Then firm 1 should invest until its marginal revenue of the public good is equal to its marginal costs. Given this investment of firm 1, firm 2 should invest nothing because its marginal revenue and its marginal costs are the same as for firm 1. Generally, if firm 1 is in an optimum given to the investment of firm 2, then firm 2 is also in an optimum given to the investment of firm 1. This fact yields the infinite number of possible equilibria. ${ }^{7}$

In the next proposition we show the properties of an asymmetric equilibrium. For simplicity, we only address the case of two firms $\{i,-i\}$. A generalization to $\mathrm{N}$ firms is straightforward.

Proposition 3. Suppose that firm i's constant marginal costs for investing in the public good are lower than the constant marginal costs of firm $-i$

$$
\frac{\partial K_{i}^{y}}{\partial y_{i}}<\frac{\partial K_{-i}^{y}}{\partial y_{-i}}
$$

In the unique Nash Equilibrium both firms produce the same quantity of the private good $\left(x_{i}^{*}=x_{-i}^{*}\right)$ and only firm $i$ invests in the public good $\left(y_{i}^{*}=Y^{*} ; y_{-i}^{*}=\right.$ $0)$ if the following condition is fulfilled

\footnotetext{
${ }^{7}$ The technical assumption in Proposition 2 ensures that the best response functions with respect to the private good are a contraction mapping.
} 


$$
(N-1)\left|x_{i} \frac{\partial^{2} p}{\partial x_{i} \partial x_{j}}+\frac{\partial p}{\partial x_{j}}\right|+N\left|x_{i} \frac{\partial^{2} p}{\partial x_{i} \partial y_{j}}+\frac{\partial p}{\partial y_{j}}\right|+\left(\frac{\partial^{2} p}{\partial x_{i} \partial x_{i}} x_{i}+2 \frac{\partial p}{\partial x_{i}}\right)<\frac{\partial^{2} K^{x}\left(x_{i}\right)}{\partial x_{i} \partial x_{i}}
$$

Proof. See Appendix.

In the following we first check whether the described equilibrium is indeed an equilibrium. Afterwards, we show that this equilibrium is unique.

Suppose that the firms choose $\left(x_{i}^{*}=x_{-i}^{*}, y_{i}^{*}=Y^{*}, y_{-i}^{*}=0\right)$. With respect to the private good we know that the marginal costs of $i$ and $-i$ are equal at the point $x_{i}^{*}=x_{-i}^{*}$. What can we say about the marginal revenues? With respect to the marginal revenue of the private good we know that it does not matter whether firm $i$ or $-i$ invests in the public good. Only the resulting quality of the public good $Y=y_{i}+y_{-i}$ is important. Therefore, the marginal revenue with respect to the private good is the same for both firms. Thus, both firms produce the same quantity of the private good.

Furthermore, suppose that firm $i$ 's optimal response to $y_{-i}^{*}=0$ is $y_{i}^{*}=Y^{*}$ given $x_{i}^{*}=x_{-i}^{*}$. This is an equilibrium if firm $-i$ has no incentive to deviate from $y_{-i}^{*}=0$. We know that the optimal response of firm $i$ implies that

$$
\left.x_{i} \frac{\partial p}{\partial y_{i}}\right|_{x_{i}^{*}=x_{-i}^{*}, y_{i}=Y_{i}^{*} y_{-i}^{*}=0}=\frac{\partial K_{i}^{y}}{\partial y_{i}} .
$$

Furthermore, we know that the marginal revenue with respect to the public good is the same for both firms with $x_{i}^{*}=x_{-i}^{*}$. Hence, if firm $-i$ has higher constant marginal costs than firm $i$, then it directly follows that

$$
\left.x_{-i} \frac{\partial p}{\partial y_{-i}}\right|_{x_{i}^{*}=x_{-i}^{*}, y_{i}=Y_{i}^{*} y_{-i}^{*}=0}<\frac{\partial K_{-i}^{y}}{\partial y_{-i}} .
$$

Therefore, it is indeed optimal for firm $-i$ to choose $y_{-i}=0$. Hence, $x_{i}^{*}=$ $x_{-i}^{*}, y_{i}=Y^{*}, y_{-i}=0$ is an equilibrium. 
Uniqueness follows from the iterated deletion of strictly dominated strategies. ${ }^{8}$ Assume that firm $i$ invests nothing $\left(y_{i}=0\right)$ and denote the best response of firm $-i$ as $\left.\widetilde{y}_{-i}\right|_{y_{i}=0}$. This is the maximal value of $y_{-i}$ that makes sense for firm $-i$ because if $y_{i}>0$, then it follows $\left.\widetilde{y}_{-i}\right|_{y_{i}>0}<\left.\widetilde{y}_{-i}\right|_{y_{i}=0}$. Hence, all $y_{-i}>\left.\widetilde{y}_{-i}\right|_{y_{i}=0}$ are strictly dominated by $y_{-i}^{a}=\left.\widetilde{y}_{-i}\right|_{y_{i}=0}$. Given this, the smallest $y_{i}$ that firm $i$ should choose is $\left.\widetilde{y}_{i}\right|_{y_{-i}^{a}}$. This is the best response to $y_{-i}^{a}$. Hence, all $y_{i}<\left.\widetilde{y}_{i}\right|_{y_{-i}} ^{a}$ are strictly dominated by $y_{i}^{a}=\left.\widetilde{y}_{i}\right|_{y_{-i}^{a}}$. Given this, firm $-i$ should maximal invest $\left.\widetilde{y}_{-i}\right|_{y_{i}^{a}}<y_{-i}^{a}$. Hence, all $y_{-i}>\left.\widetilde{y}_{-i}\right|_{y_{i}^{a}}$ are strictly dominated by $\left.\widetilde{y}_{-i}\right|_{y_{i}^{a}}=y_{-i}^{b}$. It is obvious that this process converges to the unique equilibrium where $y_{i}=Y^{*}$ and $y_{-i}=0$.

\section{Government Intervention}

Let us now consider the effects of government intervention. Assume that the government starts to invest or changes its investment in the public good. This is not a hypothetical assumption as one can see from the direct US Government support for Linux. For example, the US government decided to finance a research project at a university to improve Linux (Evans and Reddy (2003)). In the following we assume that the government can invest directly in the public good as the firms. By $y_{G}$ we denote the investment of the government in the public good.

If the government increases its investment in the public good, one usually expects a crowding out in such a way that the firms decrease their investment in the public good. At least, this is what the standard public good literature states in the context of households. ${ }^{9}$ In these models households have a certain budget. They have to decide how to allocate their budget between a private and a public good. In an interior equilibrium each household splits up his budget in such a way that his marginal utility of the private good is equal to his marginal utility of the public good. Suppose that the government increases its public good investment. Usually this decreases the marginal utility of the public good. Therefore, households shift money from the investment in the public good to the consumption of the private good in such a way that the marginal utilities are again equal. Thus, a crowding

\footnotetext{
${ }^{8}$ Uniqueness of $x_{i}^{*}=x_{-i}^{*}$ follows from the technical condition in the Proposition 3. This yields that the best response functions with respect to the private good are a contracting mapping.

$9^{9}$ see e.g. Bergstrom et.al. (1985)
} 
out occurs.

In this section we show that such a crowding out does not have to occur in our setup. Instead, a crowding in is possible. ${ }^{10}$ Thus, a higher government investment in the public good can yield a higher investment of the firms in the public good.

In order to understand how the government investment influences the incentive of a firm to invest in the public good, we have to distinguish between direct and indirect effects. Therefore, we take the total derivative of the first order conditions:

Total derivative of $\frac{\partial \pi_{i}}{\partial x_{i}}$

$$
\overbrace{+\left[\frac{\partial p}{\partial X_{-i}}+x_{i} \frac{\partial^{2} p}{\partial x_{i} \partial X_{-i}}\right] d X_{-i}+\left[\frac{\partial p}{\partial x_{i}}+x_{i} \frac{\partial^{2} p}{\partial x_{i}^{2}}-\frac{\partial^{2} K\left(x_{i}\right)}{\partial x_{i}^{2}}\right] d x_{i}+\overbrace{\left.\left[\frac{\partial p}{\partial y_{i}}+x_{i} \frac{\partial^{2} p}{\partial x_{i} \partial y_{i}}\right] d y_{i} \frac{\partial^{2} p}{\partial x_{i} \partial Y_{-i}}\right] d Y_{-i}}^{\text {direct effects }}=0 .}^{\text {indirect effect }}
$$

Total derivative of $\frac{\partial \pi_{i}}{\partial y_{i}}$

$$
\begin{aligned}
& \overbrace{\left[\frac{\partial p}{\partial y_{i}}+x_{i} \frac{\partial^{2} p}{\partial x_{i} \partial y_{i}}\right] d x_{i}}^{\text {indirect effect }}+\left[x_{i} \frac{\partial^{2} p}{\partial y_{i}^{2}}-\frac{\partial^{2} K_{i}\left(y_{i}\right)}{\partial y_{i}^{2}}\right] d y_{i} \\
& \overbrace{+\left[x_{i} \frac{\partial^{2} p}{\partial y_{i} \partial X_{-i}}\right] d X_{-i}+\left[x_{i} \frac{\partial^{2} p}{\partial y_{i} \partial Y_{-i}}\right] d Y_{-i}}^{\text {direct effects }}=0,
\end{aligned}
$$

with

$$
d X_{-i}=\sum_{j=1, i \neq j}^{N} d x_{j} \text { and } d Y_{-i}=\sum_{j=1, i \neq j}^{N} d y_{j}+d y_{G} .
$$

\footnotetext{
${ }^{10}$ Because one can consider several different cases, we restrict our attention to only two examples which highlight the possible outcomes.
} 
Equation (22) and (23) illustrate the decomposition into direct and indirect effects.

1. The direct effect influences $x_{i}\left(y_{i}\right)$ by a change in $X_{-i}$ and $Y_{-i}$ without depending on a change in the corresponding complement $y_{i}\left(x_{i}\right)$.

2. The indirect effect influences the optimal level of $x_{i}\left(y_{i}\right)$ by a change in the corresponding complement $y_{i}\left(x_{i}\right)$.

For an illustration, suppose that IBM, a producer of hardware like computer servers, faces an exogenous increase in the quality of the complementary public good Linux. For example, IBM learns that the government finances a research project at a university in order to improve Linux. We denote this by $d y_{G}>0$. How does this exogenous shock influences IBM's incentives to produce the private good and to invest in the public good? On the one hand, the government investment in the public good increases the consumers' valuation of IBM's hardware. This gives IBM an incentive to increase its production of the hardware (= a direct effect of $d Y_{-i}$ on $\left.d x_{i}\right)$. On the other hand, the additional public good investment may decrease IBM's incentive to invest in the public good because keeping the old investment level leads to an inefficient high quality of the public good from IBM's point of view ( $=$ a direct effect of $d Y_{-i}$ on $d y_{i}$ ). Furthermore, indirect effects appear. If IBM produces more servers, this changes its incentive to invest in the public good Linux (=indirect effect of $d x_{i}$ on $d y_{i}$ ). Additionally, if IBM changes its investment in Linux, the quality of Linux changes. This has an effect on IBM's incentive to produce the private good (= indirect effect of $d y_{i}$ on $d x_{i}$ ).

As we show in the following proposition, these direct and indirect effects can yield a crowding in.

Proposition 4. Suppose that the government increases its public good investment $d y_{G}>0$. Each firm increases its private good production and its public good investment if

- the marginal revenue of the public good is constant $\left(\frac{\partial^{2} p}{\partial y_{i}^{2}}=0\right)$;

- the marginal production costs of the public good are increasing $\left(\frac{\partial^{2} K_{i}^{y}}{\partial y_{i}^{2}}>0\right)$;

- the cross derivative of the price is non-negative $\left(\frac{\partial^{2} p}{\partial y_{i} \partial x_{i}} \geq 0\right)$. 
Proof. See Appendix.

The firms are in an equilibrium before the government changes its investment. In this equilibrium the marginal costs of the public good are equal to the marginal revenue of the public good. If the government increases its investment in the public good, then the marginal revenue with respect to the public good does not change $\left(\frac{\partial^{2} p}{\partial y_{i}^{2}}=0\right)$. Therefore, the firms have no direct incentive to adjust their investment in the public good. Nevertheless, if the quality of the public good increases, then the firms have an incentive to increase their production of the private good (=direct effect) because the private good's price increases. This higher private good output has a feedback-effect (= indirect effect) on the incentives to invest in the public good. A firm's marginal revenue of the public good increases if the firm produces more of the private good. Finally, the investment of the government yields a higher public good investment of the firms. Hence, no crowding out, but a crowding in occurs. Furthermore, the total supply of the private good increases.

As a second case we consider the opposite to a crowding in. We show that a total crowding out might occur. Hence, firms reduce their investment in the public good in such a way that the quality of the public good remains constant. In addition, this yields no change in the private good production.

Proposition 5. Suppose that the government increases its public good investment $d y_{G}$. Each firm does not change its private good production and the public good investment of the firms gets adjusted in such a way that a total crowding out occurs $\sum_{i=1}^{N} d y_{i}=-d y_{G}$ if

- the marginal revenue of the public good is decreasing $\left(\frac{\partial^{2} p}{\partial y_{i}^{2}}<0\right)$;

- the marginal production costs of the public good are constant $\left(\frac{\partial^{2} K_{i}^{y}}{\partial y_{i}^{2}}=0\right)$ and

- the change in the government investment is not higher then the total investment of the firms $\sum_{i=1}^{N} y_{i}^{*}>d y_{G}$.

Proof. From Proposition 2 and 3 we know that the investment in the public good has always to sum up to $Y^{*}$ with constant marginal costs. The last condition ensures that the firms' new optimal investment level remains non-negative. 
Given constant marginal costs and a decreasing marginal revenue of the public good, there exists an intersection where marginal revenue is equal to marginal costs. This point determines the individually optimal investment level in the public good. If the government increases its investment in the public good, then the marginal costs are higher than the marginal revenue because the marginal revenue decreases. Therefore, the firms have an incentive to decrease their investment in the public good. They should decrease their investment until the marginal costs are again equal to marginal revenue. This is achieved by a total crowding out. Finally, the quality of the public good does not change. This leads to no adjustment of the private good production. From a welfare point of view, the consumers do not benefit from the government intervention. Only the firms are better off. They invest less in the public good. Nevertheless, they get the same price for their proprietary product as before. In this case the investment of the government only increases the profits of the firms. The government investment has neither an impact on the firms' production of the private good nor on the quality of the public good.

\section{$5 \quad$ Market Entry}

Let us now turn to the effects of market entry. In the last section we have assumed that the firms face a given exogenous shock with respect to the quality of the public good. Given market entry, the dimension of this shock is determined endogenously. Furthermore, market entry changes the total supply of the private good. Therefore, we use a linear-quadratic framework to solve this game analytically. Hence, we use the following inverse demand function

$$
p=A-b X+c Y .
$$

In this function $b$ and $c$ represent weight factors. They determine the impact of the private good and the impact of the public good on the market price. One can easily derive such a demand function from the following maximization problem of a representative consumer

$$
\max _{x, z} U=(A+c y) x-\frac{1}{2} b x^{2}+z \text { s.t. } z+x p=m
$$


Furthermore, we consider $N$ identical firms that have the same quadratic cost functions

$$
\begin{aligned}
& K^{x}\left(x_{i}\right)=d x_{i}^{2}, \\
& K^{y}\left(y_{i}\right)=f y_{i}^{2} .
\end{aligned}
$$

The parameters $d$ and $f$ represent the weight of the cost functions in the profit function.

In the following we introduce Lemma 1 to ensure an interior solution of this game.

Lemma 1. There exists a unique Nash Equilibrium $\left(x^{*}, y^{*}\right)$ where each firm chooses the same $x_{i}^{*}$ and $y_{i}^{*}$ if the following conditions are fulfilled:

Case 1: If $f \geq \frac{c^{2}}{2 b}$, then it has to be true that $N<\frac{3 b+2 d-\frac{c^{2}}{f}}{b-\frac{c^{2}}{2 f}}$.

Case 2: If $f<\frac{c^{2}}{2 b}$, then it has to be true that $N<\frac{b+2 d}{-b+\frac{1}{2 f}}$.

Proof. See Appendix.

The conditions in Lemma 1 are always easily to fulfill because one can find a sufficiently high $d$ for each value of $N$. Intuitively, Lemma 1 ensures that the firms' best reply functions are a contraction mapping. This is the case if the costs of the private good have enough weight, so $d$ is high enough.

To find the optimal values $\left(x_{i}^{*} ; y_{i}^{*}\right)$, we write down the profit function of a firm $i$. We denote by $x_{j}$ and $y_{j}$ the production of firm $j \in\{1, \ldots, N\} \backslash i$

$$
\pi_{i}=x_{i}\left(A-b x_{i}-(N-1) b x_{j}+c y_{i}+(N-1) c y_{j}\right)-d x_{i}^{2}-f y_{i}^{2} .
$$

The first-order conditions are

$$
\begin{gathered}
\frac{\partial \pi_{i}}{\partial x_{i}}=A-2 b x_{i}-(N-1) b x_{j}+c y_{i}+(N-1) c y_{j}-2 d x_{i}=0, \\
\frac{\partial \pi_{i}}{\partial y_{i}}=c x_{i}-2 f y_{i}=0 .
\end{gathered}
$$


Solving (31) for $y_{i}^{*}$ yields

$$
y_{i}^{*}=\frac{c}{2 f} x_{i} .
$$

Equation (32) shows that $y_{i}^{*}$ depends on the firm's own production of the private good, on the weight of the public good cost function $f$, and on the impact of the public good on the price. Therefore, the optimal level of $y_{i}^{*}$ is independent of the production of the other firms and changes only if $x_{i}^{*}$ changes. This follows from the fact that the cross derivative of the price is zero. We summarize this observation in Lemma 2.

Lemma 2. A firm $i$ 's optimal public good investment $y_{i}^{*}$ depends only on its private good production

$$
y_{i}^{*}=\frac{c}{2 f} x_{i} .
$$

Intuitively, a firm's public good investment increases the private good's price. The effect of $y_{i}$ on $p$ is constant and equal to $c$. Therefore, the marginal revenue of $y_{i}$ is $c x_{i}$. The marginal costs are $2 f y_{i}$. The marginal revenue has to be equal to the marginal costs in the optimum. We see that the relationship between $x_{i}$ and $y_{i}$ is linear and the constant slope depends on the weight of the public good's production cost $f$ and on the impact of $y_{i}$ on $p$.

In a next step we determine firm $i$ 's optimal private good supply. Solving (30) for $x_{i}^{*}$ and using (32) and symmetry yields the optimal private good production of firm $i$.

$$
x_{i}^{*}=\frac{A}{b(1+N)-\frac{c^{2}}{2 f} N+2 d} .
$$

After deriving the firms' optimal production and investment levels, we consider how these change due to market entry. Suppose that an additional firm enters the market that has access to the same technology as the incumbents. Hence, it can invest in the public good and it can produce the private good. The new firm's production of the private good and its investment in the public good leads to two effects. On the one hand, the price decreases because competition in the private good market gets tougher. This decreases the incentives to produce $x_{i}$. On the 
other hand, the entrant's investment in the public good increases the consumers' valuation of the private good. This yields an incentive to increase the production of the private good. Hence, it is not obvious whether an incumbent increases or decreases its production of the private good.

Proposition 6. Suppose that the number of competing firms increases.

- If the weight of the public good's production costs is relatively high $\left(f>\frac{c^{2}}{2 b}\right)$, then each incumbent reduces its production $x_{i}^{*}$ and investment $y_{i}^{*}$.

- If the weight of the public good's production costs is relatively low $\left(f<\frac{c^{2}}{2 b}\right)$, then each incumbent increases its production $x_{i}^{*}$ and investment $y_{i}^{*}$.

If $f=\frac{c^{2}}{2 b}$, then each incumbent does not change its production $x_{i}^{*}$ and investment $y_{i}^{*}$.

Proof. To prove Proposition 6 we take the first derivative of $x_{i}^{*}$ with respect to $N$.

$$
\frac{\partial x_{i}^{*}}{\partial N}=-\frac{A}{\left(b(1+N)-\frac{1}{2} \frac{c^{2}}{f} N+2 d\right)^{2}}\left(b-\frac{1}{2} \frac{c^{2}}{f}\right)
$$

We see that $\frac{\partial x_{i}^{*}}{\partial N}$ is negative if $f>\frac{c^{2}}{2 b}$, is zero if $\frac{c^{2}}{2 b}$, and is positive if $f<\frac{c^{2}}{2 b}$. Furthermore, from Lemma 2 follows that $y_{i}^{*}$ changes in the same direction as $x_{i}^{*}$.

If the weight of the public good cost function is small $\left(f<\frac{c^{2}}{2 b}\right)$ then, in equilibrium, the entrant invests so much in the public good that it makes up for its negative pecuniary externality. This leads to an increase in the price. The increase in the price yields a higher incentive to produce the private good. It directly follows that the firms increase their public good investment, too (Lemma 2). If the weight of the public good cost function is high $\left(f>\frac{c^{2}}{2 b}\right)$, then the opposite is true.

Let us now consider the total supply of the private good $X^{*}$ and the quality of the public good $Y^{*}$. By taking the derivative with respect to $N$, we see that $X^{*}$ and $Y *$ are increasing in $N$. 


$$
\begin{aligned}
& \frac{\partial X^{*}}{\partial N}=\frac{A *[b+2 d]}{\left[b(1+N)-\frac{1}{2} \frac{c^{2}}{f} N+2 d\right]^{2}}>0 \\
& \Rightarrow \frac{\partial Y^{*}}{\partial N}>0(\text { Lemma } 2)
\end{aligned}
$$

We see that the entrant's production is always high enough to make up for a possible decline in the incumbents' production and investment. Hence, if the number of firms increases, then the total production of the private good and the quality of the public good increases. However, even if the total supply of the private good always increases in $N$, the market price does not have to decrease. Hence, counter-intuitively, market entry can increase the price of the private good.

Proposition 7. Suppose that the number of competing firms increases.

- If the weight of the public good's production costs is relatively high $\left(f>\frac{c^{2}}{2 b}\right)$, then the price $p$ decreases.

- If the weight of the public good's production costs is relatively low $\left(f<\frac{c^{2}}{2 b}\right)$, then the price $p$ increases.

If $f=\frac{c^{2}}{2 b}$, then the price does not change.

Proof. See Appendix.

Intuitively, we know that an increase in the private good production decreases the price and that a higher investment level in the public good increases the price. Hence, it depends on the dimension of the two effects whether the price increases or decreases. If the weight of the public good cost function is relatively low, then the firms invest so much in the public good that the price increases. If weight of the public good cost function is relatively high, then the opposite is true.

Let us now consider the firms' profits. We know that in a "normal" CournotGame, i.e. without a public good, incumbents dislike market entry because the entrant has a negative pecuniary externality. In contrast, in our setup the entrant has also a positive pecuniary externality by investing in the public good. Hence, it is not obvious whether the negative or positive effect dominates. 
Proposition 8. Suppose that the number of competing firms increases.

- If the weight of the public good's production costs is relatively high $\left(f>\frac{c^{2}}{2 b}\right)$, then the profits of the incumbents decrease.

- If the weight of the public good's production costs is relatively low $\left(f<\frac{c^{2}}{2 b}\right)$, then the profits of the incumbents increase.

If $f=\frac{c^{2}}{2 b}$, then the profits of the incumbents do not change.

Proof. See Appendix.

We know from Proposition 6 that market entry reduces each firm's production and investment if the weight of the public good cost function is high $\left(f>\frac{c^{2}}{2 b}\right)$. Furthermore, the price decreases. Hence, it is obvious that the profits of the incumbents decrease. This is in line with the usual effect of tougher competition. If $f<\frac{c^{2}}{2 b}$, we get the surprising result that the incumbents prefer more competition. This is due to the fact that the entrant does not only produce the private good, but also invests in the public good. Hence, the entrant has a positive and negative externality on the incumbents. If the weight of the public good cost function is small, the positive external effect dominates the negative one.

Usually higher market prices and higher profits are indices for a lower consumer surplus and a lower social welfare. Hence, one might think that welfare reacts ambiguously to market entry due to the fact that the price and the profits can increase with market entry. Nevertheless, we show that market entry unambiguously increases social welfare.

Proposition 9. If the number of competing firms increases, then the social welfare increases.

Proof. See Appendix.

If we consider the consumer surplus, we see that it increases in $N$. This is due to two effects. Firstly, the quality of the public good increases if market entry occurs. This leads to a higher private good valuation, which has a positive effect on the consumer surplus. Secondly, market entry leads to tougher competition in the proprietary sector. This increases the supply and has again a positive effect on the consumer surplus. Thus, even if the market entry leads to higher prices, we 
get a higher consumer surplus. Proposition 8 shows that market entry increases the profits of the firms if the public good's production costs have a low weight. Hence, social welfare increases. If the firms' profits decrease with market entry, the gain in the consumer surplus dominates. Therefore, market entry is always welfare enhancing.

\section{Conclusion}

In this paper we have studied the incentive to invest in a non-excludable public good that is complementary to a private good. We have shown that an increase of the government investment in the public good leads to ambiguous results. Firms may decrease their investment and a crowding out may occur. In this case the government investment is a strategic substitute to the investment of the firms. However, it is also possible that it is a strategic complement. Hence, firms may invest more in the public good if the government increases its public good investment. This leads to the following policy implication: If a government thinks about supporting Open Source Software by directly investing, then the concern that a crowding out occurs can be without any reason. Exactly the opposite can be true. The government investment can induce the firms to increase their investment in the public good and to increase their private good supply. Furthermore, we have considered market entry. We have shown that an entrant has positive and negative pecuniary externalities on the incumbents. Therefore, market entry can increase the profits of the incumbents.

Our analysis sheds new light on the incentives to license a proprietary product to horizontal competitors. Usually it is argued that licensing gives incumbents a commitment device to higher quality or, in network industries, to a bigger network by inducing competition. This results in an overall higher demand and offsets the loss in market power. ${ }^{11}$ Another argument arises from our paper. A firm can use licensing to induce market entry. The incumbent anticipates that the entrant does not only produce the private good, but also invests in public goods like e.g. cooperative advertising. This public good investment can make up for the tougher competition in the proprietary sector. Hence, it may increase the incumbent's

\footnotetext{
${ }^{11}$ See e.g. Shepard (1987) and Economides (1997).
} 
profit.

In this context, we would highlight the advertising campaign of Apple in the year 1981 as an example of such a "warm welcome" of competition. Apple Computer had responded to the entry of IBM in the PC Market with full-page newspaper advertisements, "Welcome IBM. Seriously."(See Figure 1). In these advertisements Apple claims that there will be a huge market as soon as the people understand the value of a PC. It seems that Apple thought that IBM will help them to convince people, "We look forward to responsible competition in the massive effort to distribute this American technology to the world". This is in line with our argumentation if one interprets the meaning of "responsible competition" as helping to convince people, and not as selling only proprietary products. Hence, IBM takes part in the private provision of the non-excludable public good "knowledge" or "awareness". 


\section{Welcome, IBM. Seriously.}

Welcome to the most exciting and important marketplace since the computer revolution began 35 years ago.

And congratulations on your first personal computer.

Putting real computer power in the hands of the individual is already improving the way people work, think, learn, communicate and spend their leisure hours.

Computer literacy is fast becoming as fundamental a skill as reading or writing.

When we invented the first personal computer system. we estimated that over $140,000,000$ people worldwide could justify the purchase of one, if only they understood its benefits. Next year alone, we project that well over $1,000,000$ will come to that understanding. Over the next decade, the growth of the personal computer will continue in logarithmic leaps.

We look forward to responsible competition in the massive effort to distribute this American technology to the world. And we appreciate the magnitude of your commitment.

Because what we are doing is increasing social capital by enhancing individual productivity.

Welcome to the task.

apple

Figure 1: Advertisement of Apple

\section{Appendix}

\section{Proof of Proposition 1:}

We proceed in two steps. Firstly, we prove existence. Secondly, we show uniqueness.

\section{Existence:}

Given $x_{i} \in\left[0 ; \bar{x}_{i}\right]$ and $y_{i} \in\left[0 ; \bar{y}_{i}\right]$, it follows that the strategy spaces are nonempty compact convex subsets of $R^{2}$. Furthermore, by assumption, the profit function is continuous. Given a strictly concave profit function, it follows directly that the profit functions satisfy the quasi-concavity criteria. It follows that there 
exists a Nash equilibrium in pure strategies (Debreu (1952)).

2. Uniqueness

To show uniqueness we apply the contraction mapping approach. Due to Bertsekas (1999) it is sufficient to show that the Hessian of the profit functions fulfills the "diagonal dominance" condition.

$$
H=\left|\begin{array}{ccccccc}
\frac{\partial^{2} \pi_{1}}{\partial x_{1} \partial x_{1}} & \frac{\partial^{2} \pi_{1}}{\partial x_{1} \partial y_{1}} & \frac{\partial^{2} \pi_{1}}{\partial x_{1} \partial x_{2}} & \frac{\partial^{2} \pi_{1}}{\partial x_{1} \partial y_{2}} & \ldots & \frac{\partial^{2} \pi_{1}}{\partial x_{1} \partial x_{n}} & \frac{\partial^{2} \pi_{1}}{\partial x_{1} \partial y_{n}} \\
\frac{\partial^{2} \pi_{1}}{\partial y_{1} \partial x_{1}} & \frac{\partial^{2} \pi_{1}}{\partial y_{1} \partial y_{1}} & \frac{\partial^{2} \pi_{1}}{\partial y_{1} \partial x_{2}} & \frac{\partial^{2} \pi_{1}}{\partial y_{1} \partial y_{2}} & \ldots & \frac{\partial^{2} \pi_{1}}{\partial y_{1} \partial x_{n}} & \frac{\partial^{2} \pi_{1}}{\partial y_{1} \partial y_{n}} \\
\frac{\partial^{2} \pi_{2}}{\partial x_{2} \partial x_{1}} & \frac{\partial^{2} \pi_{2}}{\partial x_{2} \partial y_{1}} & \frac{\partial^{2} \pi_{2}}{\partial x_{2} \partial x_{2}} & \frac{\partial^{2} \pi_{2}}{\partial x_{2} \partial y_{2}} & \ldots & \frac{\partial^{2} \pi_{2}}{\partial x_{2} \partial x_{n}} & \frac{\partial^{2} \pi_{2}}{\partial x_{2} \partial y_{n}} \\
\frac{\partial^{2} \pi_{2}}{\partial y_{2} \partial x_{1}} & \frac{\partial^{2} y_{2}}{\partial y_{2} \partial y_{1}} & \frac{\partial^{2} \pi_{2}}{\partial y_{2} \partial x_{2}} & \frac{\partial^{2} \pi_{2}}{\partial y_{2} \partial y_{2}} & \ldots & \frac{\partial^{2} \pi_{2}}{\partial y_{2} \partial x_{n}} & \frac{\partial^{2} \pi_{2}}{\partial y_{2} \partial y_{n}} \\
\ldots & \ldots & \ldots & \ldots & \ldots & \ldots & \ldots \\
\frac{\partial^{2} \pi_{n}}{\partial x_{n} \partial x_{1}} & \frac{\partial^{2} \pi_{n}}{\partial x_{n} \partial y_{1}} & \frac{\partial^{2} \pi_{n}}{\partial x_{n} \partial x_{2}} & \frac{\partial^{2} \pi_{n}}{\partial x_{n} \partial y_{2}} & \ldots & \frac{\partial^{2} \pi_{n}}{\partial x_{n} \partial x_{n}} & \frac{\partial^{2} \pi_{n}}{\partial x_{n} \partial y_{n}} \\
\frac{\partial^{2} \pi_{n}}{\partial y_{n} \partial x_{1}} & \frac{\partial^{2} \pi_{n}}{\partial y_{n} \partial y_{1}} & \frac{\partial^{2} \pi_{n}}{\partial y_{n} \partial x_{2}} & \frac{\partial^{2} \pi_{n}}{\partial y_{n} \partial y_{2}} & \ldots & \frac{\partial^{2} \pi_{n}}{\partial y_{n} \partial x_{n}} & \frac{\partial^{2} \pi_{n}}{\partial y_{n} \partial y_{n}}
\end{array}\right|
$$

Therefore, the diagonal of the Hessian dominates the off-diagonal entries if

$$
\sum_{j=1, i \neq j}^{N}\left|\frac{\partial^{2} \pi_{i}}{\partial x_{i} \partial x_{j}}\right|+\sum_{j=1}^{N}\left|\frac{\partial^{2} \pi_{i}}{\partial x_{i} \partial y_{j}}\right|<\left|\frac{\partial^{2} \pi_{i}}{\partial x_{i} \partial x_{i}}\right|, \forall i
$$

and if

$$
\sum_{j=1}^{N}\left|\frac{\partial^{2} \pi_{i}}{\partial y_{i} \partial x_{j}}\right|+\sum_{j=1, i \neq j}^{N}\left|\frac{\partial^{2} \pi_{i}}{\partial y_{i} \partial y_{j}}\right|<\left|\frac{\partial^{2} \pi_{i}}{\partial y_{i} \partial y_{i}}\right|, \forall i
$$

Calculating the derivatives leads to

$$
\begin{aligned}
& \sum_{j=1, i \neq j}^{N}\left|x_{i} \frac{\partial^{2} p}{\partial x_{i} \partial x_{j}}+\frac{\partial p}{\partial x_{j}}\right|+\sum_{j=1}^{N}\left|x_{i} \frac{\partial^{2} p}{\partial x_{i} \partial y_{j}}+\frac{\partial p}{\partial y_{j}}\right|<\left|\frac{\partial^{2} p}{\partial x_{i} \partial x_{i}} x_{i}+2 \frac{\partial p}{\partial x_{i}}-\frac{\partial^{2} K^{x}\left(x_{i}\right)}{\partial x_{i} \partial x_{i}}\right|, \forall i \\
& (N-1)\left|x_{i} \frac{\partial^{2} p}{\partial x_{i} \partial x_{j}}+\frac{\partial p}{\partial x_{j}}\right|+N\left|x_{i} \frac{\partial^{2} p}{\partial x_{i} \partial y_{j}}+\frac{\partial p}{\partial y_{j}}\right|<-\left(\frac{\partial^{2} p}{\partial x_{i} \partial x_{i}} x_{i}+2 * \frac{\partial p}{\partial x_{i}}\right)+\frac{\partial^{2} K^{x}\left(x_{i}\right)}{\partial x_{i} \partial x_{i}}, \forall i \\
& (N-1)\left|x_{i} \frac{\partial^{2} p}{\partial x_{i} \partial x_{j}}+\frac{\partial p}{\partial x_{j}}\right|+N\left|x_{i} \frac{\partial^{2} p}{\partial x_{i} \partial y_{j}}+\frac{\partial p}{\partial y_{j}}\right|+\left(\frac{\partial^{2} p}{\partial x_{i} \partial x_{i}} x_{i}+2 \frac{\partial p}{\partial x_{i}}\right)<\frac{\partial^{2} K^{x}\left(x_{i}\right)}{\partial x_{i} \partial x_{i}}, \forall i
\end{aligned}
$$


Calculating the derivatives leads to

$$
\begin{gathered}
\sum_{j=1, i \neq j}^{N}\left|x_{i} \frac{\partial^{2} p}{\partial y_{i} \partial x_{j}}\right|+\left|x_{i} \frac{\partial^{2} p}{\partial y_{i} \partial x_{i}}+\frac{\partial p}{\partial x_{i}}\right|+\sum_{j=1, i \neq j}^{N}\left|x_{i} \frac{\partial^{2} p}{\partial y_{i} \partial y_{i}}\right|<\left|x_{i} \frac{\partial^{2} p}{\partial y_{i} \partial y_{i}}-\frac{\partial^{2} K_{i}^{y}\left(y_{i}\right)}{\partial y_{i} \partial y_{i}}\right|, \forall i \\
(N-1)\left|x_{i} \frac{\partial^{2} p}{\partial y_{i} \partial x_{j}}\right|+\left|x_{i} \frac{\partial^{2} p}{\partial y_{i} \partial x_{i}}+\frac{\partial p}{\partial x_{i}}\right|+(N-1)\left|x_{i} \frac{\partial^{2} p}{\partial y_{i} \partial y_{j}}\right|<\left|x_{i} \frac{\partial^{2} p}{\partial y_{i} \partial y_{i}}-\frac{\partial^{2} K_{i}^{y}\left(y_{i}\right)}{\partial y_{i} \partial y_{i}}\right|, \forall i \\
(N-1)\left|x_{i} \frac{\partial^{2} p}{\partial y_{i} \partial x_{j}}\right|+\left|x_{i} \frac{\partial^{2} p}{\partial y_{i} \partial x_{i}}+\frac{\partial p}{\partial x_{i}}\right|+(1-N) x_{i} \frac{\partial^{2} p}{\partial y_{i} \partial y_{j}}<-\left(x_{i} \frac{\partial^{2} p}{\partial y_{i} \partial y_{i}}\right)+\frac{\partial^{2} K_{i}^{y}\left(y_{i}\right)}{\partial y_{i} \partial y_{i}}, \forall i \\
(N-1)\left|x_{i} \frac{\partial^{2} p}{\partial y_{i} \partial x_{j}}\right|+\left|x_{i} \frac{\partial^{2} p}{\partial y_{i} \partial x_{i}}+\frac{\partial p}{\partial x_{i}}\right|+(2-N) x_{i} \frac{\partial^{2} p}{\partial y_{i} \partial y_{j}}<\frac{\partial^{2} K_{i}^{y}\left(y_{i}\right)}{\partial y_{i} \partial y_{i}}, \forall i
\end{gathered}
$$

\section{Proof of Proposition 2}

We proceed in two steps. Firstly, we prove existence. Secondly, we show a multiplicity of equilibria.

1. Existence

See first part of the proof of Proposition 1.

2. Multiplicity

We proceed in 4 steps:

Step 1:

Due to the first technical assumption in the Proposition 2, we have a contraction mapping of the best reply functions with respect to the private good. This leads to a unique Nash Equilibrium $x^{*}=\left(x_{i}^{*}, x_{2}^{*}, \ldots, x_{N}^{*}\right)$. 
Step 2:

By the proof of existence, we know that there exists at least one Nash Equilibrium in pure strategies. Therefore, we can assume that

$$
s^{*}=\left(\left(x_{1}^{*}, y_{1}^{*}\right),\left(x_{2}^{*}, y_{2}^{*}\right), \ldots,\left(x_{j}^{*}, y_{j}^{*}\right),\left(x_{k}^{*}, y_{k}^{*}\right), \ldots,\left(x_{N}^{*}, y_{N}^{*}\right)\right)
$$

is a Nash Equilibrium in pure strategies.

Step 3:

We define $y_{j}^{\prime}=y_{j}+\mu$ and $y_{k}^{\prime}=y_{k}-\mu$ with $\mu \neq 0$.

$s^{*}$ implies that the FOCs of every firm $i \in\{1, \ldots, N\}$ has to be fulfilled at the values of $s^{*}$ :

$$
\begin{aligned}
& \left.\frac{\partial \pi_{i}}{\partial x_{i}}\right|_{s^{*}}=\frac{\partial R_{i}}{\partial x_{i}}-\frac{\partial K^{x}}{\partial x_{i}}=0 \\
& \left.\frac{\partial \pi_{i}}{\partial y_{i}}\right|_{s^{*}}=\frac{\partial R_{i}}{\partial y_{i}}-\frac{\partial K_{j}^{y}}{\partial y_{i}}=0
\end{aligned}
$$

If this is the case, then these first order conditions are also fulfilled with the values $s^{\prime}=\left(\left(x_{1}^{*}, y_{1}^{*}\right),\left(x_{2}^{*}, y_{2}^{*}\right), \ldots,\left(x_{j}^{*}, y_{j}^{\prime}\right),\left(x_{k}^{*}, y_{k}^{\prime}\right), \ldots,\left(x_{N}^{*}, y_{N}^{*}\right)\right)$.

This is the case because $Y=\sum_{i=1}^{N} y_{i}$ does not change. The marginal costs of $y_{i}$ are always constant and the same for all firms. Furthermore, the firms' marginal revenues do not change.

$$
\left.x_{i} \frac{\partial p}{\partial y_{i}}\right|_{Y}=\text { const. }
$$

This leads to the conclusion that all first order conditions are fulfilled at $s^{\prime}$.

Step 4:

Now one can go back to Step 3 and repeat the procedure with $s^{\prime}$ instead of $s^{*}$.

By repeating Step 3 and 4 it is obvious that there exist an infinite number of equilibria.

\section{Proof of Proposition 3}

Firstly, we prove that the described equilibrium is indeed a Nash Equilibrium. Secondly, we show that this is the unique Nash Equilibrium by ruling out all other possible equilibria. 
1. Is $\left(x_{i}^{*}=x_{-i}^{*}, y_{i}=Y^{*}, y_{-i}^{*}=0\right)$ an equilibrium?

The FOC of the firms with respect to the public good is

$$
\frac{\partial \pi_{j}}{\partial y_{j}}=x_{j}^{*} \frac{\partial p}{\partial y_{j}}-\frac{\partial K_{j}^{y}}{\partial y_{j}}=0, j \in\{i,-i\}
$$

Given $x_{i}^{*}=x_{-i}^{*}$, it follows that $x_{i}^{*} \frac{\partial p}{\partial y_{i}}=x_{-i}^{*} \frac{\partial p}{\partial y_{-i}}$. Hence, if

$$
\left.x_{i}^{*} \frac{\partial p}{\partial y_{i}}\right|_{y_{i}=Y^{*}}=\frac{\partial K_{i}^{y}}{\partial y_{i}},
$$

then

$$
\left.x_{-i}^{*} \frac{\partial p}{\partial y_{-i}}\right|_{y_{i}=Y^{*}}<\frac{\partial K_{-i}^{y}}{\partial y_{-i}} .
$$

Therefore, $\left(x_{i}^{*}=x_{-i}^{*}, y_{i}=Y^{*}, y_{-i}^{*}=0\right)$ is an equilibrium.

Next, we rule out all other possible equilibria to show uniqueness. Firstly, we show that $y_{i}$ and $y_{-i}$ are perfect strategic substitutes. The total derivative of

$$
\frac{\partial \pi_{i}}{\partial y_{i}}=x_{i} \frac{\partial p}{\partial y_{i}}-\frac{\partial K_{i}^{y}}{\partial y_{i}}=0
$$

is

$$
\left[x_{i} \frac{\partial^{2} p}{\partial y_{i}^{2}}-\frac{\partial^{2} K_{i}^{y}}{\partial y_{i}^{2}}\right] d y_{i}+\left[x_{i} \frac{\partial^{2} p}{\partial y_{i} \partial y_{-i}}-\frac{\partial^{2} K_{i}^{y}}{\partial y_{i} \partial y_{-i}}\right] d y_{-i}=0 .
$$

Due to $\frac{\partial^{2} K_{i}^{y}}{\partial y_{i}^{2}}=\frac{\partial^{2} K_{i}^{y}}{\partial y_{i} \partial y_{-i}}=0$ it is true that

$$
d y_{i}=-d y_{-i}
$$

Secondly, we solve the game by iterated deletion of strictly dominated strategies. We denote by $\left.y_{i}^{*}\right|_{y_{-i}=0}$ the optimal response of firm $i$ to $y_{-i}=0$. Because of $\frac{\partial K_{i}^{y}}{\partial y_{i}}<\frac{\partial K_{-i}^{y}}{\partial y_{-i}}$, it follows that $\left.y_{-i}^{*}\right|_{y_{i}=0}<\left.y_{i}^{*}\right|_{y_{-i}=0}$.

Hence, firm $i$ knows that firm $-i$ never chooses a higher $y_{-i}$ than $\left.y_{-i}^{*}\right|_{y_{i}=0}=y_{-i}^{\max }$.

Given this, firm $i$ should at least choose $y_{i}^{\min }=\left.y_{i}^{*}\right|_{y_{-i}=0}-y_{-i}^{\max }$.

Hence, firm $-i$ knows that firm $i$ never invests less than $y_{i}^{\text {min }}$.

Given this, firm $-i$ should never choose a higher $y_{-i}$ than $y_{-i}^{\max }=\left.y_{-i}^{*}\right|_{y_{i}=y_{i}^{m i n}}$.

Hence, firm $i$ knows that firm $-i$ never chooses a higher $y_{-i}$ than $y_{-i}^{\max }$.

Given this, the smallest $y_{i}$ that firm $i$ should choose is $y_{i}^{\min ^{\prime}}=\left.y_{i}^{*}\right|_{y_{-i}=0}-y_{-i}^{m a x}$. 
Continuing, one sees that in the limit $y_{i}^{\min }$ converges to $\left.y_{i}^{*}\right|_{y_{-i}=0}$ and $y_{-i}^{\max }$ converges to 0 . Hence, $\left\{\left(x_{1}^{*},\left.y_{1}^{*}\right|_{y_{2}=0}\right),\left(x_{2}^{*}, y_{2}^{*}=0\right)\right\}$ with $\left.y_{1}^{*}\right|_{y_{2}=0}>\left.y_{2}^{*}\right|_{y_{1}=0}$ is the unique Nash Equilibrium.

\section{Proof of Proposition 4}

For the proof we proceed in two steps. Firstly, we show that $\frac{\partial x_{i}}{\partial y_{G}}>0$. Secondly, we prove that $\frac{\partial y_{i}}{\partial y_{G}}>0$.

1. Using the implicit function theorem combined with symmetry yields

$$
\frac{\partial x_{i}}{\partial y_{G}}=\frac{\partial x_{1}}{\partial y_{G}}=\frac{\left|D_{x}\right|}{|D|}
$$

with

$$
\left|D_{x}\right|=
$$

$\begin{array}{|cccccccccc|}\partial f^{1} / \partial y_{G} & \partial f^{1} / \partial y_{1} & \partial f^{1} / \partial x_{2} & \partial f^{1} / \partial y_{2} & \ldots & \ldots & \partial f^{1} / \partial x_{N-1} & \partial f^{1} / \partial y_{N-1} & \partial f^{1} / \partial x_{N} & \partial f^{1} / \partial y_{N} \\ \partial g^{1} / \partial y_{G} & \partial g^{1} / \partial y_{1} & \partial g^{1} / \partial x_{2} & \partial g^{1} / \partial y_{2} & \ldots & \ldots & \partial g^{1} / \partial x_{N-1} & \partial g^{1} / \partial y_{N-1} & \partial g^{1} / \partial x_{N} & \partial g^{1} / \partial y_{N} \\ \partial f^{2} / \partial y_{G} & \partial f^{2} / \partial y_{1} & \partial f^{2} / \partial x_{2} & \partial f^{2} / \partial y_{2} & \ldots & \ldots & \partial f^{2} / \partial x_{N-1} & \partial f^{2} / \partial y_{N-1} & \partial f^{2} / \partial x_{N} & \partial f^{2} / \partial y_{N} \\ \partial g^{2} / \partial y_{G} & \partial g^{2} / \partial y_{1} & \partial g^{2} / \partial x_{2} & \partial g^{2} / \partial y_{2} & \ldots & \ldots & \partial g^{2} / \partial x_{N-1} & \partial f^{4} / \partial y_{N-1} & \partial g^{2} / \partial x_{N} & \partial g^{2} / \partial y_{N} \\ \partial f^{N} / \partial y_{G} & \partial f^{N} / \partial y_{1} & \partial f^{N} / \partial x_{2} & \partial f^{N} / \partial y_{2} & \ldots & \ldots & \partial f^{N} / \partial x_{N-1} & \partial f^{N} / \partial y_{N-1} & \partial f^{N} / \partial x_{N} & \partial f^{N} / \partial y_{N} \\ \partial g^{N} / \partial y_{G} & \partial g^{N} / \partial y_{1} & \partial g^{N} / \partial x_{2} & \partial g^{N} / \partial y_{2} & \ldots & \ldots & \partial g^{N} / \partial x_{N-1} & \partial g^{N} / \partial y_{N-1} & \partial g^{N} / \partial x_{N} & \partial g^{N} / \partial y_{N}\end{array} \mid$

and

$$
|D|=
$$

$\begin{array}{|cccccccccc|}\partial f^{1} / \partial x_{1} & \partial f^{1} / \partial y_{1} & \partial f^{1} / \partial x_{2} & \partial f^{1} / \partial y_{2} & \ldots & \ldots & \partial f^{1} / \partial x_{N-1} & \partial f^{1} / \partial y_{N-1} & \partial f^{1} / \partial x_{N} & \partial f^{1} / \partial y_{N} \\ \partial g^{1} / \partial x_{1} & \partial g^{1} / \partial y_{1} & \partial g^{1} / \partial x_{2} & \partial g^{1} / \partial y_{2} & \ldots & \ldots & \partial g^{1} / \partial x_{N-1} & \partial g^{1} / \partial y_{N-1} & \partial g^{1} / \partial x_{N} & \partial g^{1} / \partial y_{N} \\ \partial f^{2} / \partial x_{1} & \partial f^{2} / \partial y_{1} & \partial f^{2} / \partial x_{2} & \partial f^{2} / \partial y_{2} & \ldots & \ldots & \partial f^{2} / \partial x_{N-1} & \partial f^{2} / \partial y_{N-1} & \partial f^{2} / \partial x_{N} & \partial f^{2} / \partial y_{N} \\ \partial g^{2} / \partial x_{1} & \partial g^{2} / \partial y_{1} & \partial g^{2} / \partial x_{2} & \partial g^{2} / \partial y_{2} & \ldots & \ldots & \partial g^{2} / \partial x_{N-1} & \partial f^{4} / \partial y_{N-1} & \partial g^{2} / \partial x_{N} & \partial g^{2} / \partial y_{N} \\ \cdot & . & . & . & . & . & . & . & . & \\ \partial f^{N} / \partial x_{1} & \partial f^{N} / \partial y_{1} & \partial f^{N} / \partial x_{2} & \partial f^{N} / \partial y_{2} & \ldots & \ldots & \partial f^{N} / \partial x_{N-1} & \partial f^{N} / \partial y_{N-1} & \partial f^{N} / \partial x_{N} & \partial f^{N} / \partial y_{N} \\ \partial g^{N} / \partial x_{1} & \partial g^{N} / \partial y_{1} & \partial g^{N} / \partial x_{2} & \partial g^{N} / \partial y_{2} & \ldots & \ldots & \partial g^{N} / \partial x_{N-1} & \partial g^{N} / \partial y_{N-1} & \partial g^{N} / \partial x_{N} & \partial g^{N} / \partial y_{N}\end{array} \mid$

where $f^{i}=\frac{\partial \pi_{i}}{\partial x_{i}}$ for $i \in\{1,2,3, \ldots, N\}$ and $g^{i}=\frac{\partial \pi_{i}}{\partial y_{i}}$ for $i \in\{1,2,3, \ldots, N\}$.

For the proof that

$$
\frac{\partial x_{i}}{\partial y_{G}}=\frac{\left|D_{x}\right|}{|D|}>0
$$


we show that the numerator and denominator are positive.

$1.1\left|D_{x}\right|>0$

Using the conditions from Proposition 4 we can substitute:

$$
\begin{aligned}
& -\frac{\partial f^{i}}{\partial y_{G}}=-a \forall i \in\{1,2,3, \ldots, N\} \\
& \frac{\partial f^{i}}{\partial y_{w}}=a \forall i \in\{1,2,3, \ldots, N\}, \forall w \in\{1,2,3, \ldots, N\} \\
& \frac{\partial f^{i}}{\partial x_{z}}=c \forall i \in\{1,2,3, \ldots, N\}, \forall z \in\{1,2,3, \ldots, N\} \backslash i \\
& \frac{\partial f^{i}}{\partial x_{i}}=e \forall i \in\{1,2,3, \ldots, N\} \\
& \frac{\partial g^{i}}{\partial y_{G}}=0 \forall i \in\{1,2,3 \ldots, N\} \\
& \frac{\partial g^{i}}{\partial y_{i}}=b \forall z \in\{1,2,3, \ldots, N\} \\
& \frac{\partial g^{i}}{\partial x_{z}}=d \forall i \in\{1,2,3, \ldots, N\}, \forall z \in\{1,2,3, \ldots, N\} \\
& \left|\begin{array}{cccccccccccc}
-a & a & c & a & c & a & \ldots & \ldots & c & a & c & a \\
0 & b & d & 0 & d & 0 & \ldots & \ldots & d & 0 & d & 0 \\
-a & a & e & a & c & a & \ldots & \ldots & c & a & c & a \\
0 & 0 & a & b & d & 0 & \ldots & \ldots & d & 0 & d & 0 \\
-a & a & c & a & e & a & \ldots & \ldots & c & a & c & a \\
0 & 0 & d & 0 & a & b & \ldots & \ldots & d & 0 & d & 0 \\
. & . & . & . & . & . & . & . & . & . & . & . \\
. & . & . & . & . & . & . & . & . & . & . & . \\
-a & a & c & a & c & a & \ldots & \ldots & e & a & c & a \\
0 & 0 & d & 0 & d & 0 & \ldots & \ldots & a & b & d & 0 \\
-a & a & c & a & c & a & \ldots & \ldots & c & a & e & a \\
0 & 0 & d & 0 & d & 0 & \ldots & \ldots & d & 0 & a & b
\end{array}\right|
\end{aligned}
$$


By subtracting line 1 from all lines $z$ with $z \in\{3,5,7, \ldots, N-1\}$ we derive

$$
\left|\begin{array}{cccccccccccc}
-a & a & c & a & c & a & \ldots & \ldots & c & a & c & a \\
0 & b & d & 0 & d & 0 & \ldots & \ldots & d & 0 & d & 0 \\
0 & 0 & e-c & 0 & 0 & 0 & \ldots & \ldots & 0 & 0 & 0 & 0 \\
0 & 0 & a & b & d & 0 & \ldots & \ldots & d & 0 & d & 0 \\
0 & 0 & 0 & 0 & e-c & 0 & \ldots & \ldots & 0 & 0 & 0 & 0 \\
0 & 0 & d & 0 & a & b & \ldots & \ldots & d & 0 & d & 0 \\
. & . & . & . & . & . & . & . & . & . & . & . \\
. & . & . & . & . & . & . & . & . & . & . & . \\
0 & 0 & 0 & 0 & 0 & 0 & \ldots & \ldots & e-c & 0 & 0 & 0 \\
0 & 0 & d & 0 & d & 0 & \ldots & \ldots & a & b & d & 0 \\
0 & 0 & 0 & 0 & 0 & 0 & \ldots & \ldots & 0 & 0 & e-c & 0 \\
0 & 0 & d & 0 & d & 0 & \ldots & \ldots & d & 0 & a & b
\end{array}\right|
$$

One sees that there exists a line $z(z \in\{3,5,7, \ldots N\})$ where only the element in the $\mathrm{z}$ row is not zero. Therefore, we use theses lines to derive a upper triangle matrix:

$$
\left|\begin{array}{cccccccccccc}
-a & a & c & a & c & a & \ldots & \ldots & c & a & c & a \\
0 & b & 0 & 0 & d & 0 & \ldots & \ldots & d & 0 & d & 0 \\
0 & 0 & e-c & 0 & 0 & 0 & \ldots & \ldots & 0 & 0 & 0 & 0 \\
0 & 0 & 0 & b & d & 0 & \ldots & \ldots & d & 0 & d & 0 \\
0 & 0 & 0 & 0 & e-c & 0 & \ldots & \ldots & 0 & 0 & 0 & 0 \\
0 & 0 & 0 & 0 & 0 & b & \ldots & \ldots & d & 0 & d & 0 \\
. & . & . & . & . & . & . & . & . & . & . & . \\
. & . & . & . & . & . & . & . & . & . & . & . \\
0 & 0 & 0 & 0 & 0 & 0 & \ldots & \ldots & e-c & 0 & 0 & 0 \\
0 & 0 & 0 & 0 & 0 & 0 & \ldots & \ldots & 0 & b & d & 0 \\
0 & 0 & 0 & 0 & 0 & 0 & \ldots & \ldots & 0 & 0 & e-c & 0 \\
0 & 0 & 0 & 0 & 0 & 0 & \ldots & \ldots & 0 & 0 & 0 & b
\end{array}\right|
$$

Hence, the Determinant is

$$
\left|D_{x}\right|=-a b^{N}(e-c)^{N-1}
$$

Substituting back gives if $\mathrm{N}$ even: 


$$
\left|D_{x}\right|=-\overbrace{\left[\frac{\partial p}{\partial y_{i}}+x_{i} \frac{\partial^{2} p}{\partial y_{i} \partial x_{i}}\right]\left[x_{i} \frac{\partial^{2} p}{\partial y_{i}^{2}}-\frac{\partial^{2} K_{i}\left(y_{i}\right)}{\partial y_{i}^{2}}\right]^{N}\left[\frac{\partial p}{\partial x_{i}}-\frac{\partial K_{i}\left(x_{i}\right)}{\partial x_{i}^{2}}\right]^{N-1}>0}^{+}-
$$

if $\mathrm{N}$ uneven:

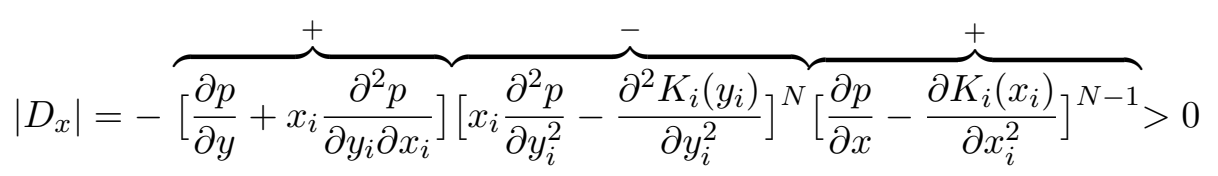

Therefore if follows $\left|D_{x}\right|>0 \forall N$.

$1.2|D|>0$

\begin{tabular}{|c|c|c|c|c|c|c|c|c|c|}
\hline$\partial f^{1} / \partial x_{1}$ & $\partial f^{1} / \partial y_{1}$ & $\partial f^{1} / \partial x_{2}$ & $\partial f^{1} / \partial y_{2}$ & $\cdots$ & $\cdots$ & $\partial f^{1} / \partial x_{N-1}$ & $\partial f^{1} / \partial y_{N-1}$ & $\partial f^{1} / \partial x_{N}$ & $\partial f^{1} / \partial y_{N}$ \\
\hline$\partial f^{2} / \partial x_{1}$ & $\partial f^{2} / \partial y_{1}$ & $\partial f^{2} / \partial x_{2}$ & $\partial f^{2} / \partial y_{2}$ & $\cdots$ & $\ldots$ & $\partial f^{2} / \partial x_{N-1}$ & $\partial f^{2} / \partial y_{N-1}$ & $\partial f^{2} / \partial x_{N}$ & $\partial f^{2} / \partial y_{N}$ \\
\hline$\partial f^{3} / \partial x_{1}$ & $\partial f^{3} / \partial y_{1}$ & $\partial f^{3} / \partial x_{2}$ & $\partial f^{3} / \partial y_{2}$ & $\cdots$ & $\cdots$ & $\partial f^{3} / \partial x_{N-1}$ & $\partial f^{3} / \partial y_{N-1}$ & $\partial f^{3} / \partial x_{N}$ & $\partial f^{3} / \partial y_{N}$ \\
\hline$\partial f^{4} / \partial x_{1}$ & $\partial f^{4} / \partial y_{1}$ & $\partial f^{4} / \partial x_{2}$ & $\partial f^{4} / \partial y_{2}$ & $\cdots$ & $\cdots$ & $\partial f^{4} / \partial x_{N-1}$ & $\partial f^{4} / \partial y_{N-1}$ & $\partial f^{4} / \partial x_{N}$ & $\partial f^{4} / \partial y_{N}$ \\
\hline$\partial f^{N} / \partial x_{1}$ & $\partial f^{N} /$ & $\partial f^{N} / \partial x_{2}$ & $\partial f^{N}$ & $\ldots$ & $\ldots$ & $\partial f^{N} / \partial x_{N-1}$ & $\partial f^{N} / \partial y_{N-1}$ & $\partial f^{N} / \partial x_{N}$ & $\partial f^{N} / \partial y_{N}$ \\
\hline
\end{tabular}

$$
|D|=
$$

We know that this matrix is diagonally dominant. Furthermore, if a matrix is diagonal dominant and its diagonal elements are positive, then the matrix is positive definite. On the diagonal, there are the second-order conditions that are all negative. Through multiplying every line by $(-1)$ one gets positive diagonal elements and through the odd number of lines a scalar of +1 . This gives a positive definite matrix. Therefore, the determinant has to be positive.

2.

Total derivative of $\frac{\partial \pi_{i}}{\partial y_{i}}$ :

$$
\text { indirect effect }
$$

$$
\begin{aligned}
& \overbrace{\left[\frac{\partial p}{\partial y_{i}}+x_{i} \frac{\partial^{2} p}{\partial x_{i} \partial y_{i}}\right] d x_{i}}+\left[x_{i} \frac{\partial^{2} p}{\partial y_{i}^{2}}-\frac{\partial^{2} K_{i}\left(y_{i}\right)}{\partial y_{i}^{2}}\right] d y_{i} \\
& \text { direct effects } \\
& \overbrace{+\left[x_{i} \frac{\partial^{2} p}{\partial y_{i} \partial X_{-i}}\right] d X_{-i}+\left[x_{i} \frac{\partial^{2} p}{\partial y_{i} \partial Y_{-i}}\right] d Y_{-i}}=0
\end{aligned}
$$


One sees that the direct effect of $d Y_{-i}$ is zero. The direct effect of $d X_{-i}$ is non-negative. The indirect effect of $d x_{i}$ is positive. Therefore, $y_{i}$ has to increase to ensure that $\frac{\partial \pi_{i}}{\partial y_{i}}$ remains zero.

\section{Proof of Lemma 1}

The existence of a Nash-Equilibrium in pure strategies follows immediately from Proposition 1. For the uniqueness we apply the contraction mapping principle. Beforehand, we reduce the strategy space form $R^{2}$ to $R$ because $y_{i}$ is directly determined through $x_{i}$. To see this we write down the FOC with respect to the public good

$$
\frac{\partial \pi_{i}}{\partial y_{i}}=c x_{i}-2 f y_{i}=0
$$

Rewriting leads to

$$
y_{i}=\frac{c}{2 f} x_{i}
$$

Plugging back into the profit function of firm $i$ yields

$$
\pi_{i}=x_{i}\left(A-b x_{i}-b \sum_{j=1 ; i \neq j}^{N} x_{j}+c \frac{c}{2 f} x_{i}+c \sum_{j=1 ; i \neq j}^{N} \frac{c}{2 f} x_{j}\right)-d x_{i}^{2}-f\left(\frac{c}{2 f} x_{i}\right)^{2} .
$$

The first order conditions of the $\mathrm{N}$ firms with respect to the private good are a contraction mapping if

$$
\begin{gathered}
\sum_{j=1 ; i \neq j}^{N}\left|\frac{\partial^{2} \pi_{i}}{\partial x_{i} \partial x_{j}}\right|<\left|\frac{\partial^{2} \pi_{i}}{\partial x_{i}^{2}}\right| \forall i \in\{1, \ldots, N\}, \\
(N-1)\left|-b+\frac{c^{2}}{2 f}\right|<\left|-2 b-2 d+\frac{c^{2}}{2 f}\right| .
\end{gathered}
$$

If $f \geq \frac{c^{2}}{2 b}$, then $-b+\frac{c^{2}}{2 f} \leq 0$. Therefore:

$$
\begin{gathered}
(1-N)\left(-b+\frac{c^{2}}{2 f}\right)<2 b+2 d-\frac{c^{2}}{2 f} \\
N<\frac{3 b+2 d-\frac{c^{2}}{f}}{b-\frac{c^{2}}{2 f}}
\end{gathered}
$$


If $f<\frac{c^{2}}{2 b}$, then $-b+\frac{c^{2}}{2 f}>0$. Therefore:

$$
\begin{gathered}
(N-1)\left(-b+\frac{c^{2}}{2 f}\right)<2+2 d-\frac{1}{2 f} \\
N<\frac{b+2 d}{\frac{c^{2}}{2 f}-b}
\end{gathered}
$$

\section{Proof of Proposition 7}

For the proof we use the fact that $y_{i}=\frac{c}{2 f} x_{i}(32)$ and rewrite the demand function (25) as follows:

$$
\begin{gathered}
p=A-b X+c Y=A-b X(N)+c \frac{c}{2 f} X(N)=A+X(N)\left(-b+\frac{c^{2}}{2 f}\right) \\
p=A+N * \frac{A}{b(1+N)-\frac{1}{2} \frac{c^{2}}{f} N+2 d}\left(-b+\frac{c^{2}}{2 f}\right)
\end{gathered}
$$

Now we can take the first derivative of $p$ with respect to $N$ yields

$$
\frac{\partial p}{\partial N}=\left(-b+\frac{c^{2}}{2 f}\right) * \frac{A(b+2 d)}{\left[b(1+N)-\frac{1}{2} \frac{c^{2}}{f} N+2 d\right]^{2}} .
$$

Therefore:

- $\frac{\partial p}{\partial N}<0$ if $f>\frac{c^{2}}{2 b}$

- $\frac{\partial p}{\partial N}=0$ if $f=\frac{c^{2}}{2 b} \rightarrow p=A$

- $\frac{\partial p}{\partial N}>0$ if $f<\frac{c^{2}}{2 b}$

\section{Proof of Proposition 8}

$$
\begin{gathered}
\pi_{i}=p * x_{i}-d x^{2}-f\left[\frac{1}{2 f} x_{i}\right]^{2}=p * x_{i}-x_{i}^{2}\left(d+\frac{1}{4 f}\right) \\
\pi_{i}=\frac{A^{2}\left(b+d-\frac{c^{2}}{4 f}\right)}{\left(b(1+N)-\frac{c^{2}}{2 f} N+2 d\right)^{2}}
\end{gathered}
$$




$$
\frac{\partial \pi_{i}}{\partial N}=\frac{A^{2}\left(b-\frac{c^{2}}{2 f}\right)\left(-2 b-2 d+\frac{c^{2}}{2 f}\right)}{\left(b(1+N)-\frac{c^{2}}{2 f} N+2 d\right)^{3}}
$$

The last term $\left(-2 b-2 d+\frac{c^{2}}{2 f}\right)$ is always negative due to the second order conditions. Therefore, we have to look at $b-\frac{c^{2}}{2 f}$ and at the denominator.

Case 1: $f=\frac{c^{2}}{2 b}$

Then $b-\frac{c^{2}}{2 f}=0$ and therefore $\frac{\partial \pi}{\partial N}=0$.

Case 2: $f>\frac{c^{2}}{2 b}$

Then $b-\frac{c^{2}}{2 f}>0$ and the sign of $\frac{\partial \pi}{\partial N}$ depends on $N$ due to $b(1+N)-\frac{c^{2}}{2 f} N+2 d$. This term is always positive

$$
b(1+N)-\frac{c^{2}}{2 f} N+2 d=b+N\left(b-\frac{c^{2}}{2 f}\right)+2 d .
$$

Therefore, $\frac{\partial \pi}{\partial N}<0$ for all $N>0$.

Case 3: $f<\frac{c^{2}}{2 b}$

Then $b-\frac{c^{2}}{2 f}<0$ and the sign of $\frac{\partial \pi}{\partial N}$ depends on $N$ due to the term $b(1+N)-$ $\frac{c^{2}}{2 f} N+2 d$.

This term is zero if

$$
N=\frac{2 d+b}{\frac{c^{2}}{2 f}-b}>0 .
$$

The slope of $b(1+N)-\frac{c^{2}}{2 f} N+2 d$ with respect to $\mathrm{N}$ is

$$
\frac{\partial\left(b(1+N)-\frac{c^{2}}{2 f} N+2 d\right)}{\partial N}=b-\frac{c^{2}}{2 f}<0 .
$$

Therefore, $\frac{\partial \pi}{\partial N}>0$ in the relevant area where $N<\frac{2 d+b}{\frac{c^{2}}{2 f}-b}$ (Lemma 1).

\section{Proof of Proposition 9}

Firstly, we calculate the consumer surplus

$$
C S=(A+c Y-p) X 0.5=0.5 b X^{2} .
$$


The total surplus is the sum of the firms' profits and the consumers' surplus

$$
\begin{gathered}
T S=N * \pi_{i}+C S, \\
\frac{\partial T S}{\partial N}=\frac{\partial\left(N * \pi_{i}\right)}{\partial N}+\frac{\partial C S}{\partial N}, \\
\frac{d T S}{d N}=A^{2} \frac{b N\left(d+\frac{c^{2}}{4 f}\right)+\left(b+d-\frac{c^{2}}{4 f}\right)\left(b+.5 \frac{c^{2}}{f} N+2 d\right)}{\left(b(1+N)-.5 \frac{c^{2}}{f} N+2 d\right)^{3}}>0 .
\end{gathered}
$$




\section{References}

Becker, G. S. And K. M. Murphy [1993], "A Simple Theory of Advertising as a Good or Bad", The Quarterly Journal of Economics, 108(4), 941 - 964.

Bergstrom, T.C. L.E. Blume and H.R. Varian [1986], "On the Private Provision of a Public Goods", Journal of Public Economics, 29, 25 - 49.

Bertsekas D.P. [1999], "Nonlinear Programming", Athena Scientific.

Bulow, J. I., J. D. Geanakoplos and P. D. Klemperer [1985], "Multimarket Oligopoly: Strategic Substitutes and Complements", The Journal of Political Economy, 93(3), 488 - 511.

Bitzer, J. And P. Schröeder [2002], "Bug-Fixing and Code-Writing: The Private Provision of Open Source Software", DIW Discussion Papers, No. 296.

Debreu D. [1952], "A social equilibrium existence theorem", Proceedings of the National Academy of Siences, 38, 886 - 893.

Economides, N. [1997], "Network Externalities, Complementarities, and Invitations to Enter", European Journal of Political Economy, 12(2), 211 - 233.

Evans, D. And B. Reddy [2002], "Government Policy towards Open Source Software: A Solution in Search of a Problem", $n / e / r / a$ Consulting Economists Working Paper.

Friedman, J.W. [1983], "Advertising and Oligopolistic Equilibrium", The Bell Journal of Economics, 50(2), 197 - 234.

Hahn, W. (EDITOR) [2002], "Government Preferences for Promoting Open Source Software", AEI Brooking Joint Center for Regulatory Studies, Washington D.C.

Johnson, J. P. [2002], "Open Source Software: Private Provision of a Public Good", Journal of Economics and Management Strategy, 11(4), 637 - 662.

Lerner, J. And J. Tirole [2002], "Some Simple Economics of Open Source", Journal of Industrial Economics, 14(2), 464 - 473. 
Mendys-Kamphorst, E. [2003], "Open Source, Complementarities and Software Quality", mimeo.

Schmidt, K. M. And M. Schnitzer [2002], "Public Subsidies for Open Source? Some Economic Policy Issues", Harvard Journal of Law and Technology, 16(2), $473-505$.

Shepard, A. [1987], "Licensing to Enhance Demand for New Technologies", Rand Journals of Economics, 18(3), 360 - 368. 